\title{
HIDRÓLISE PARCIAL DA SUPERFÍCIE DO polyethylene terephthalate (PET): TRANSFORMANDO UM REJEITO EM UM MATERIAL DE TROCA CATIÔNICA PARA APLICAÇÃO AMBIENTAL
}

\author{
Marcelo G. Rosmaninho, Erika Jardim, Gilmara L. Ferreira, Maria H. Araújo e Rochel M. Lago* \\ Departamento de Química, Instituto de Ciências Exatas, Universidade Federal de Minas Gerais, 31270-901 Belo Horizonte - MG, \\ Brasil \\ Flávia C. C. Moura \\ Departamento de Química, Instituto de Ciências Exatas e Biológicas, Universidade Federal de Ouro Preto, 35400-000 Ouro Preto \\ - MG, Brasil
}

Recebido em 15/10/08; aceito em 5/2/09; publicado na web em 3/7/09

\begin{abstract}
PARTIAL HYDROLYSIS OF PET SURFACE: TRANSFORMING A PLASTIC WASTE INTO A MATERIAL WITH CATIONIC EXCHANGE PROPERTIES FOR ENVIRONMENTAL APPLICATION. In this work it is proposed a simple and versatile undergraduate chemical experiment in polymer and environmental technology based on the process of polyethylene terephthalate (PET) hydrolysis. Polyethylene terephthalate from post-consume bottles is submitted to a controlled partial hydrolysis which allows the students to follow the reaction by a simple procedure. The students can explore the reaction kinetics, the effect of catalysts and the exposed polyethylene terephthalate surface area on the hydrolysis reaction. The second and innovative part of this experiment is the technological and environmental application of the hydrolyzed polyethylene terephthalate as a material with cation exchange properties. The surface hydrolyzed polyethylene terephthalate can be used as adsorbent for cationic contaminants.
\end{abstract}

Keywords: undergraduate laboratory, PET, catalysis.

\section{INTRODUÇÃO}

O PET (polietilenotereftalato) é considerado um dos mais importantes polímeros de engenharia das duas últimas décadas, devido ao rápido crescimento de sua utilização. ${ }^{1}$ As embalagens de garrafas plásticas de PET são ideais para o acondicionamento de alimentos, devido às suas propriedades de barreiras que impossibilitam a troca de gases e absorção de odores externos, mantendo as características originais dos produtos envasados. Além disso, são leves, versáteis e $100 \%$ recicláveis. A introdução da embalagem de PET no Brasil, em 1988, além de trazer as indiscutíveis vantagens ao consumidor, trouxe também o desafio de sua reciclagem. ${ }^{2}$

O PET é um dos polímeros mais reciclados em todo o mundo devido à sua extensa gama de aplicações, tais como fibras têxteis, tapetes, carpetes, não-tecidos, embalagens, filmes, fitas, cordas, compostos, e mesmo incinerado para produção de energia. ${ }^{3-6}$ No Brasil, em 2006, alcançamos o segundo lugar na reciclagem do PET, com aproximadamente $51 \%$ das embalagens pós-consumo efetivamente recicladas (193,9 mil toneladas das 378 produzidas), perdendo apenas para o Japão, que reciclou $62 \%$.

A reciclagem química do PET tem atraído a atenção dos químicos devido à grande variedade de processos, resultando em diferentes produtos. Por exemplo, o PET pode ser reciclado por hidrólise catalítica, ${ }^{7}$ aminólise,${ }^{8}$ alcoólise,${ }^{9}$ glicólise ${ }^{10}$ e mesmo para a produção de copolímeros através da reação com outros polímeros. ${ }^{11}$ Uma comparação destas diferentes rotas, produtos obtidos e suas aplicações na indústria química é discutida em uma recente revisão. ${ }^{1}$

Dentro deste contexto, o desenvolvimento de novos processos para reciclagem de polímeros é, atualmente, uma área relevante de pesquisa acadêmica e tecnológica devido a duas necessidades importantes: a redução do volume crescente de rejeitos de polímeros originados de diferentes fontes e, a conversão de fontes de baixo custo, e.g. rejeitos plásticos, em materiais de valor agregado com

*e-mail: rochel@ufmg.br aplicações tecnológicas. Experimentos para a graduação, mostrando a aplicação da química na transformação de rejeitos de polímeros em novos materiais com aplicações especiais, são de grande relevância para estimular estudantes nessa importante área de pesquisa. Vários experimentos têm sido propostos na literatura focando a completa despolimerização do PET e a recuperação dos seus monômeros. ${ }^{12,13}$

Neste trabalho, é apresentado um experimento para alunos de graduação onde garrafas de PET são convertidas, por um processo simples de hidrólise catalítica parcial das cadeias superficiais de poliéster, em um material com propriedades de troca catiônica e que pode ter diversas aplicações industriais e ambientais (Figura 1).

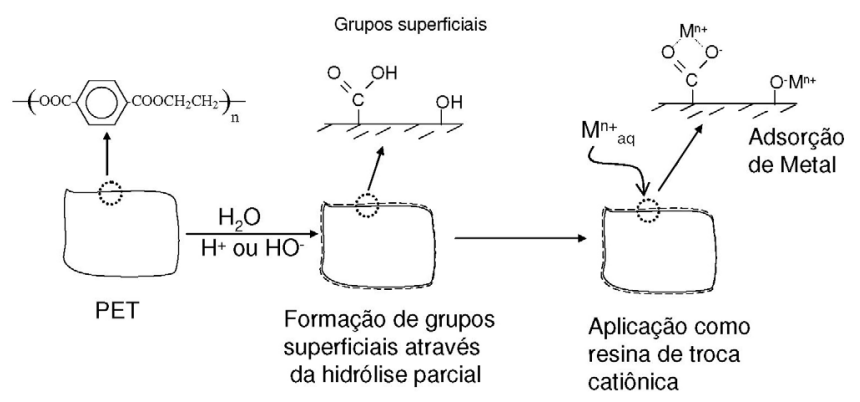

Figura 1. Hidrólise da superfície do PET produzindo grupos - $\mathrm{COOH}$ e - $\mathrm{OH}$ e o processo de adsorção de espécies catiônicas nestes grupos

O experimento permite a contextualização de diversos tópicos em química e propõe aos estudantes explorar diversos aspectos, tais como a reação de hidrólise e sua cinética, o efeito da natureza e da concentração do catalisador, área superficial exposta do PET, a caracterização da superfície do PET por titulação simples e a aplicação do PET parcialmente hidrolisado como adsorvente de contaminantes catiônicos em água. Este experimento é mais adequado para estudantes do terceiro e quarto anos de graduação com conhecimentos 
básicos em química de polímeros, reações orgânicas (isto é, hidrólise de ésteres) e processos de adsorção.

O material suplementar traz detalhes sobre a teoria de hidrólise de PET, detalhes experimentais, sugestão de aplicação em uma turma de estudantes e algumas análises mais específicas dos materiais obtidos.

\section{PARTE EXPERIMENTAL}

\section{Preparação do PET para a hidrólise}

O PET incolor (por exemplo, $2 \mathrm{~g}$ de garrafas de refrigerante) deverão ser cortados em pedaços quadrangulares de 5 x $5 \mathrm{~mm}$ (ou 20, 10 e $2 \mathrm{~mm}$ ). A hidrólise ocorre sob refluxo de $1 \mathrm{~g}$ de PET e $5 \mathrm{~mL}$ de solução aquosa de ácido ou base, $\mathrm{HNO}_{3}$ ou NaOH .

\section{A purificação do PET após hidrólise}

A purificação do PET após a hidrólise é uma etapa muito importante, uma vez que todos os resultados discutidos são dependentes da purificação do PET parcialmente hidrolisado. Após a hidrólise ácida os passos seguintes são necessários: lavar com solução de $\mathrm{NaOH}$ para solubilizar o ácido tereftálico sólido e removê-lo da superfície do PET; lavar com $\mathrm{HNO}_{3}$ para regenerar os grupos carboxílicos superficiais; lavar com água destilada para tirar o excesso de $\mathrm{HNO}_{3}$ e secar em forno a $100{ }^{\circ} \mathrm{C}$ por $4 \mathrm{~h}$.

\section{Determinação dos sítios ácidos por titulação}

Para determinação dos sítios ácidos, $30 \mathrm{mg}$ de PET parcialmente hidrolisado são reagidos com $\mathrm{NaOH}\left(0,0500 \mathrm{~mol} \mathrm{~L}^{-1}\right)$ e o excesso é titulado com solução de biftalato de potássio $0,00150 \mathrm{~mol} \mathrm{~L}^{-1}$ usando fenolftaleina como indicador.

\section{Experimentos de adsorção}

Os experimentos de adsorção são feitos com soluções aquosas de azul de metileno ou $\mathrm{CdCl}_{2}\left(20 \mathrm{~mL}\right.$ de 5 a $\left.400 \mathrm{mg} \mathrm{L}^{-1}\right)$ adicionados a $30 \mathrm{mg}$ de PET parcialmente hidrolisado em frasco fechado por 12 h. A quantidade de azul de metileno adsorvido foi monitorada por espectrofotômetro UV-Vis em $\lambda_{\text {max }} 627 \mathrm{~nm}$ e a concentração de $\mathrm{Cd}^{2+}$ determinada por absorção atômica.

\section{Cuidados}

Cuidado especial deve ser tomado com as soluções básicas e ácidas concentradas. Óculos de segurança, luvas e avental de laboratório devem ser usados em todo o experimento. Especial cuidado com soluções concentradas de $\mathrm{HNO}_{3}$, que liberam vapores ácidos altamente tóxicos e irritantes.

Detalhes de todo processo experimental estão disponíveis no Material Suplementar.

\section{RESULTADOS E DISCUSSÃO}

A transformação do PET é baseada na hidrólise superficial do poliéster. A hidrólise parcial pode ser monitorada pelos estudantes simplesmente pela pesagem do PET não hidrolisado após a reação. Isso permite o estudo da cinética, do mecanismo e do efeito de diferentes parâmetros da reação, tais como o tipo e concentração do catalisador e a área superficial do PET exposta. Uma idéia geral das etapas deste trabalho que podem ser executadas pelos estudantes é apresentada na Figura 2.

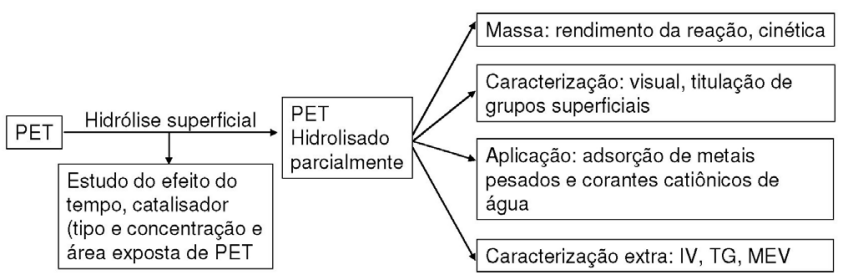

Figura 2. Idéia geral das etapas deste trabalho

\section{A hidrólise do PET}

A hidrólise completa do PET é catalisada por ácidos ou bases produzindo ácido tereftálico (AT) e etilenoglicol (EG) (Equação 1):

$$
\begin{aligned}
& {\left[-\mathrm{OOC}-\bigcirc-{\mathrm{COO}-\mathrm{CH}_{2} \mathrm{CH}_{2-}}_{\mathrm{n}}^{-} \stackrel{\mathrm{H}_{2} \mathrm{O}}{\longrightarrow} \mathrm{HOOC}-\bigcirc-\mathrm{COOH}+\mathrm{HOCH}_{2} \mathrm{CH}_{2} \mathrm{OH}\right.} \\
& \text { PET } \\
& \text { Ácido tereftálico (AT) Etilenoglicol (EG) }
\end{aligned}
$$

Neste trabalho, as condições de reação são controladas para produzir somente a hidrólise parcial, principalmente na superfície do PET. Para controlar a hidrólise os estudantes podem variar a temperatura e o tempo de reação, a concentração do catalisador e a área superficial de exposição do PET.

Abaixo são ilustrados alguns resultados que podem ser obtidos por alunos neste experimento.

\section{Efeito do catalisador e de sua concentração}

A Figura 3 mostra rendimentos da hidrólise (\% em peso do PET consumido na reação) para reações em presença de $\mathrm{NaOH}$ e $\mathrm{HNO}_{3}$ em diferentes concentrações.
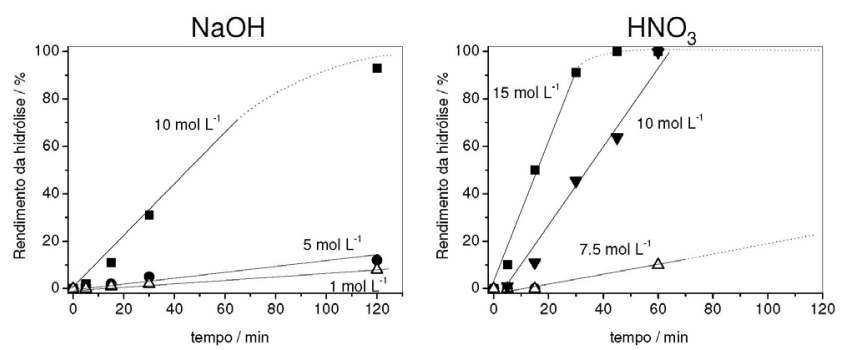

Figura 3. Hidrólise do PET na presença de $\mathrm{NaOH}$ e $\mathrm{HNO}_{3}$ em diferentes concentrações (refluxo a $120^{\circ} \mathrm{C}, 1 \mathrm{~g}$ PET em $5 \mathrm{~mL}$ solução)

Resultados similares foram obtidos para $\mathrm{NaOH}$ e $\mathrm{HNO}_{3}$. Para concentrações dos catalisadores menores que ca. $7 \mathrm{~mol} \mathrm{~L}^{-1}$ rendimentos muito baixos de hidrólise foram obtidos mesmo após $120 \mathrm{~min}$. No entanto, reações em presença de catalisadores em concentrações de $10 \mathrm{~mol} \mathrm{~L}^{-1}$ podem levar à hidrólise completa do PET. É interessante observar um comportamento linear da curva de hidrólise, especialmente nos primeiros $60 \mathrm{~min}$, sugerindo uma cinética de pseudo-ordem zero. Uma expressão simples para a velocidade de reação pode ser escrita como:

$\mathrm{V}_{\text {hidrólise }}=\mathrm{k}_{\text {hidrólise }}\left[\mathrm{H}_{2} \mathrm{O}\right]^{0}[\mathrm{PET}]^{0}[\text { catalisador }]^{0}$

A constante de velocidade $\mathrm{k}_{\text {hidrólise }}$ pode ser calculada pela inclinação da curva de hidrólise. Uma discussão mais detalhada destes dados é apresentada no Material Suplementar. 
Tabela 1. Dimensões de pedaços quadrados de PET (1), área relativa exposta e constante de velocidades de hidrólise observadas ( $k$ )

\begin{tabular}{lcc}
\hline Area relativa exposta & Constante de hidrólise \\
\hline 20 & 100 & 0.0170 \\
10 & 105 & 0.0170 \\
5 & 114 & 0.0175 \\
2 & 143 & 0.0192 \\
\hline
\end{tabular}

a- a área exposta foi calculada usando a equação $A=2 \cdot 1^{2}+(4 \cdot 1 . x)$. A área relativa exposta foi obtida considerando $1=20$ mm como referência $100 \%$ com $\mathrm{x}=0,5 \mathrm{~mm}$.

\section{O efeito da área superficial do PET exposta na velocidade de hidrólise}

O efeito da área superficial exposta do polímero pode ser investigado usando pedaços de PET com diferentes dimensões. A Tabela 1 mostra a área superficial exposta relativa do PET estimada por pedaços quadrados com diferentes dimensões (l).

Observa-se que o rendimento de hidrólise não muda significativamente quando pedaços quadrados de PET de 5, 10 e 20 mm são usados. No entanto, para pedaços de $2 \mathrm{~mm}$, onde a área superficial exposta do PET aumenta $43 \%$, um aumento significante é observado na $\mathrm{k}_{\text {hidrólise. }}$

\section{Caracterização da superfície hidrolisada do PET}

A hidrólise parcial da cadeia de poliéster produz grupos carboxílicos $(-\mathrm{COOH})$ e álcoois $(-\mathrm{OH})$ ligados à cadeia polimérica na superfície do PET. O número de grupos ácidos carboxílicos formados na superfície hidrolisada do PET pode ser determinado por titulação ácido-base (Figura 4).
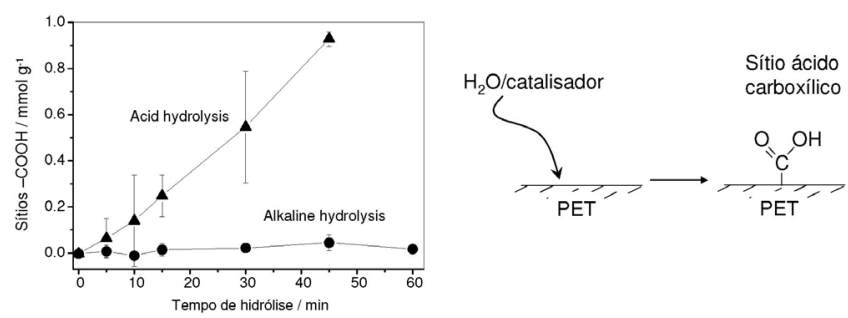

Figura 4. Sítios de ácidos carboxílicos superficiais para o PET hidrolisado com $\mathrm{HNO}_{3}$ e $\mathrm{NaOH}\left(120^{\circ} \mathrm{C}\right.$, catalisador $\left.10 \mathrm{~mol} \mathrm{~L}^{-1}\right)$

Observa-se que o PET hidrolisado com $\mathrm{HNO}_{3}$ mostra uma concentração de sítios ácidos que crescem quase linearmente com o tempo de hidrólise, alcançando aproximadamente $1 \mathrm{mmol} \mathrm{g}^{-1}{ }_{\text {PET }}$ com $45 \mathrm{~min}$ de reação. No entanto, o PET hidrolisado com $\mathrm{NaOH}$ não mostrou nenhum crescimento significativo no número de sítios ácidos após a hidrólise. A presença de sítios ácidos pela hidrólise ácida está relacionada à criação de altas concentrações de defeitos na superfície do PET, enquanto a hidrólise alcalina produz uma superfície bastante regular. Uma discussão mais detalhada destes resultados é apresentada no Material Suplementar.

\section{Estudos de adsorção}

A presença de grupos carboxílicos e hidroxilas na superfície do PET tornam estes materiais bastante interessantes para serem usados como resinas de troca catiônica. A Figura 5 mostra as isotermas de adsorção para o $\mathrm{Cd}^{2+}$ com o PET hidrolisado com $\mathrm{HNO}_{3}(10 \mathrm{~mol}$ $\mathrm{L}^{-1}, 30 \mathrm{~min}, 120^{\circ} \mathrm{C}$ ).

Observa-se que o PET não hidrolisado não adsorve $\mathrm{Cd}^{2+}$ da solu-

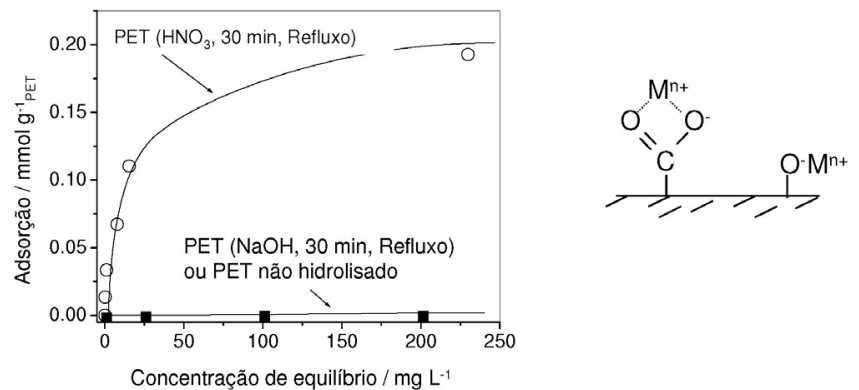

Figura 5. Isotermas de adsorção de $\mathrm{Cd}^{2+}$ no PET hidrolisado com $\mathrm{HNO}_{3}(10$ mol $L^{-1}, 30 \mathrm{~min}, 120^{\circ} \mathrm{C}$ )

ção. Por sua vez, o material hidrolisado com $\mathrm{HNO}_{3}$ mostra capacidade de adsorção de ca. 0,18 mmol $\mathrm{Cd}^{2+} \mathrm{g}^{-1}$.

Esses resultados estão diretamente relacionados à criação de sítios ácidos superficiais pela hidrólise. Estes experimentos simples de adsorção podem também ser feitos com o corante catiônico azul de metileno, uma vez que é bastante solúvel em água e os estudantes podem observar visualmente o processo de adsorção ou estudá-lo por determinações espectroscópicas. A estrutura catiônica do azul de metileno e as isotermas de adsorção do PET hidrolisado com $\mathrm{HNO}_{3}\left(10 \mathrm{~mol} \mathrm{~L}^{-1}\right)$ por $5,10,15$ e $30 \mathrm{~min}$ a 120 ${ }^{\circ} \mathrm{C}$ são mostradas na Figura 6.

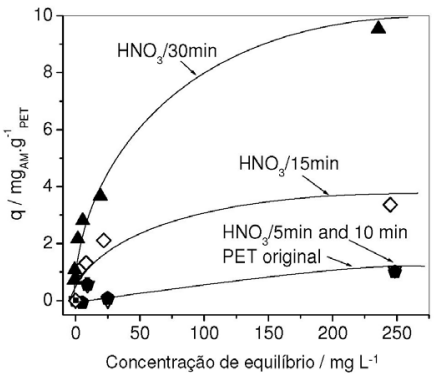

Estrutura catiônica do azul de metileno

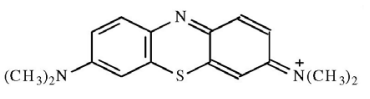

Figura 6. Isotermas de adsorção do azul de metileno no PET hidrolisado e sua estrutura química

Observa-se que o PET não hidrolisado adsorve uma quantidade muito pequena de azul de metileno. Além disso, a hidrólise para 5 e 10 min com $\mathrm{HNO}_{3}$ não causou mudança significativa nas propriedades de adsorção do PET. Todavia, para o material hidrolisado por $15 \mathrm{~min}$ a capacidade de adsorção alcança aproximadamente $3 \mathrm{mg} \mathrm{g}^{-1}$ e o PET hidrolisado por $30 \mathrm{~min}$ mostra um forte aumento na sua capacidade de adsorção para $c a .10 \mathrm{mg} \mathrm{g}^{-1}$.

\section{CONCLUSÃO}

A hidrólise parcial do PET é um experimento muito simples, per- 
mitindo aos estudantes investigarem a reação por uma determinação muito simples, isto é, o peso do PET após a hidrólise. Vários parâmetros de reação podem ser investigados, tais como a natureza e a concentração do catalisador, o tempo de reação e a área superficial exposta do PET. Também, o PET parcialmente hidrolisado pode ser caracterizado por simples titulação ácido-base para determinar os sítios de ácidos carboxílicos superficiais. Estes grupos carboxílicos superficiais podem ser usados como sítios de troca catiônica e dar uma aplicação única do PET hidrolisado como resinas de troca cationnica.

Além disso, este experimento oferece aos estudantes a possibilidade de explorar rejeitos de PET em várias maneiras: sua reciclagem por hidrólise simples para produzir ácido tereftálico e etilenoglicol e todos os problemas de suas purificações; propriedades poliméricas especialmente características superficiais e, investigação do processo de adsorção e uso de resinas de troca catiônica.

Os estudantes que participaram conosco deste experimento expressaram grande satisfação em transformar rejeitos em material com aplicação tecnológica e ambiental e, também, por usar tantos aspectos da química neste experimento. Os produtos químicos e técnicas utilizadas nos experimentos são normalmente encontrados em qualquer laboratório regular de aula prática.

\section{MATERIAL SUPLEMENTAR}

Está disponível em http://quimicanova.sbq.org.br, na forma de arquivo PDF, com acesso livre.

No Material Suplementar poderá ser encontrada toda parte experimental e, ainda, alguns resultados discutidos mais detalhadamente. Encontram-se também sugestões de como aplicar o experimento em sala de aula e uma discussão teórica sobre os aspectos abordados neste trabalho como forma de apoio para realização das discussões com os estudantes.

\section{AGRADECIMENTOS}

À CAPES, CNPq e FAPEMIG pelo suporte financeiro.

\section{REFERÊNCIAS}

1. Nikles D. E.; Farahat, M. S.; Macromol. Mat. Eng. 2005, $290,13$.

2. http://www.cempre.org.br/fichas_tecnicas.php, acessada em Novembro 2008.

3. Soderberg, D. J.; Lenton, R. A.; Boylett, A. R.; Hicks, D. A.; Cell. Polym. 1993, 12, 421.

4. Curti, P.; Ruvolo, F.; Polímeros 2006, 16, 276.

5. Mancini, S. D.; Zanin, M.; Polímeros 2002, 12, 34.

6. Alonso, J. G.; Polímeros 2005, 15, 27.

7. Kumar, S.; Guria, C. J.; Macromol. Sci. Pure Appl. Chem. 2005, 42, 237.

8. Goje, A. S.; Thakur, S. A.; Diware, V. R.; Chauhan, Y. P.; Mishra, S.;.Polym.-Plast. Technol. Eng. 2004, 43, 407.

9. Dannoux, M.; Cassagnau, P.; Michel, A.; Can. J. Chem. Eng. 2002, 80, 1075 .

10. Colomines, G.; Rivas, F.; Lacoste, M. L.; Robin, J. J.; Macromol. Mat. Eng. 2005, 290, 710.

11. Baldissera, A. E.; Valerio, C. E. S.; Basso, N. R. D.; Guaragna, F.; Einloft, S.; Tessier, M.; Fradet, A.; Quim. Nova 2005, 28, 188.

12. Kaufman, D.; Wright, G.; Kroemer, R.; Engel, J.; J. Chem. Educ. 1999 , $76,1525$.

13. Iler, H. D.; Rutt, E.; Althoff, S.; J. Chem. Educ. 2006, 83, 439 


\section{HIDRÓLISE PARCIAL DA SUPERFÍCIE DO POLYETHYLENE TEREPHTHALATE (PET): TRANSFORMANDO UM REJEITO EM UM MATERIAL DE TROCA CATIÔNICA PARA APLICAÇÃO AMBIENTAL}

\section{Marcelo G. Rosmaninho, Erika Jardim, Gilmara L. Ferreira, Maria H. Araújo e Rochel M. Lago*}

Departamento de Química, Instituto de Ciências Exatas, Universidade Federal de Minas Gerais, 31270-901 Belo Horizonte - MG, Brasil

Flávia C. C. Moura

Departamento de Química, Instituto de Ciências Exatas e Biológicas, Universidade Federal de Ouro Preto, 35400-000 Ouro Preto - MG, Brasil

\section{INTRODUÇÃO}

O desenvolvimento de novos processos para reciclagem de polímeros é, atualmente, uma área relevante de pesquisa acadêmica e tecnológica devido a duas necessidades importantes: (i) a redução do volume crescente de rejeitos de polímeros originados de diferentes fontes e (ii) a conversão de fontes de baixo custo, e.g. rejeitos plásticos, em materiais de valor agregado com aplicações tecnológicas. Experimentos de graduação mostrando a aplicação da química na transformação de rejeitos de polímeros em novos materiais com aplicações especiais são de grande relevância para estimular estudantes nessa importante área de pesquisa. ${ }^{1}$

Neste trabalho, garrafas de PET são convertidas, por um processo simples de hidrólise catalítica parcial das cadeias superficiais do poliéster, em um material com propriedades de troca catiônica e que pode ter diversas aplicações industriais e ambientais. Os estudantes são capazes de explorar vários aspectos de reações de hidrólise, caracterização da superfície do PET e sua aplicação como adsorvente de contaminantes catiônicos.

O PET (polietilenotereftalato) é considerado um dos mais importantes polímeros de engenharia das duas últimas décadas devido ao rápido crescimento de sua utilização. Por esta razão, existe uma grande necessidade de reciclagem do PET por dois motivos: ecológico e econômico. ${ }^{2}$

O PET é um polímero termoplástico e pode ser fundido e extrudado para produção de fibras, cordas, tubos e mesmo incinerado para produção de energia. ${ }^{3}$ A reciclagem química do PET tem atraído a atenção dos químicos devido à grande variedade de processos, resultando em diferentes produtos. Por exemplo, o PET pode ser reciclado por hidrólise catalítica, ${ }^{4}$ aminólise,${ }^{5}$ alcoólise,${ }^{6}$ glicólise ${ }^{7}$ e mesmo para a produção de copolímeros através da reação com outros polímeros. ${ }^{8}$ Uma comparação destas diferentes rotas, produtos obtidos e suas aplicações na indústria química é discutida na ref. 2.

\section{A hidrólise do PET}

O PET possui a função éster que pode ser hidrolisada para produzir ácido tereftálico (AT) e etilenoglicol (EG) de acordo com o processo representado na Equação 1S.

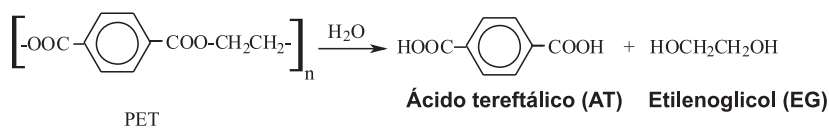

*e-mail: rochel@ufmg.br
Essa hidrólise pode ser catalisada por ácidos ou bases, e a reação acontece na interface sólido (PET)-fase aquosa. Um modelo simples considerando a reação na superfície do PET é o shrinking core, um processo no qual a partícula sólida do PET é hidrolisada em sua superfície levando a um decréscimo constante no tamanho da partícula (Figura 1S). ${ }^{9,10}$

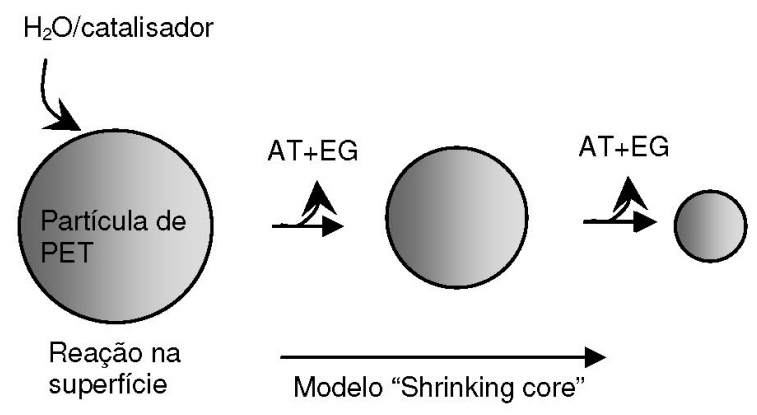

Figura 1S. Representação esquemática do modelo shrinking core para a hidrólise do PET formando ácido tereftálico (AT) e etilenoglicol (EG)

\section{O objetivo deste trabalho}

Neste trabalho, rejeitos de PET são convertidos, por um simples processo de hidrólise parcial catalítica, em um material com especiais aplicações industriais e ambientais, por exemplo, como resinas trocadoras de cátions. (Figura 2S).

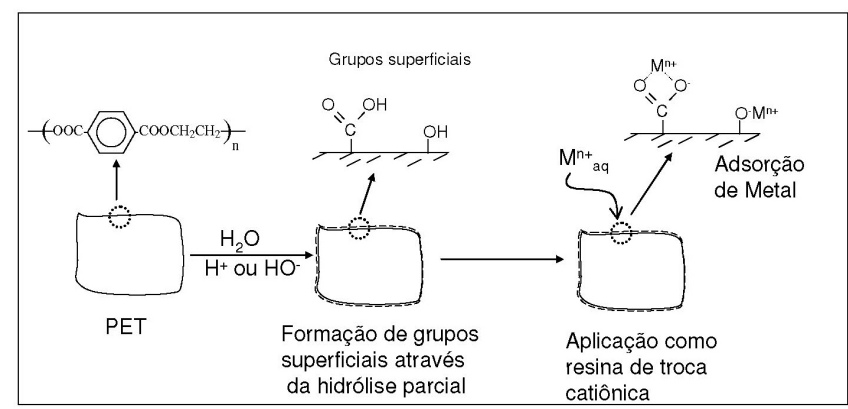

Figura 2S. Representação esquemática da hidrólise parcial do PET e sua aplicação como adsorvente de contaminante em água 
Neste experimento, os estudantes serão capazes de explorar vários aspectos: (i) reação de hidrólise e sua cinética, o efeito da natureza e concentração do catalisador, a área superficial exposta do PET (ii) a caracterização da superfície do PET por simples titulação e (iii) a aplicação do PET parcialmente hidrolisado como adsorvente de contaminantes catiônicos em água. Este experimento é mais adequado para alunos do terceiro ou quarto anos da graduação que tenham conhecimentos básicos de química de polímeros, reações orgânicas (por exemplo, hidrólise de ésteres) e processos de adsorção.

\section{PROCEDIMENTO EXPERIMENTAL}

\section{Comentários/sugestões para professores}

Este experimento pode ser dividido em 3 partes:

Primeira aula: hidrólise e purificação do PET/início da secagem.

Segunda aula: pesagem dos materiais e início do experimento de adsorção.

Terceira aula: titulação, medidas de adsorção (UV/VIS ou absorção atômica) e discussão.

Entretanto, se somente 2 aulas são disponíveis, os experimentos podem ser feitos como se segue:

Primeira aula: hidrólise e purificação do PET/ início da secagem

Segunda aula: pesagem, experimentos de adsorção (mais curtos), titulação.

A aula pode ser dividida em grupos de 3 ou 4 estudantes. Cada grupo pode fazer um experimento de hidrólise em diferente condição e adsorção de diferentes espécies, ao invés de todos fazerem o mesmo experimento.

Um exemplo simples de experimentos realizados em 3 aulas ( $2 \mathrm{~h}$ cada) com estudantes divididos em 6 grupos é dado abaixo:

Atividades da aula 1. Hidrólise com NaOH $10 \mathrm{~mol} \mathrm{~L}^{-1}$ e $\mathrm{HNO}_{3} 10$ mol L ${ }^{-1}$ variando o tempo de reação (10, 30 and $\left.60 \mathrm{~min}\right)$. Purificação do PET hidrolisado.

Atividades da aula 2. Pesagem para calcular o rendimento da hidrólise. Titulação. Preparação dos experimentos de adsorção com o corante azul de metileno e/ou com metais.

Atividades da aula 3. Análise das soluções após os experimentos de adsorção.

Esta atividade pode ser melhor visualizada na Tabela $1 \mathrm{~S}$.

Tabela 1S. Um exemplo de arranjo de experimentos a serem usados em 3 aulas com 6 grupos de estudantes

\begin{tabular}{|c|c|c|c|}
\hline Grupo & $\begin{array}{c}\text { Aula 1. Hidrólise } \\
\text { (condições) }\end{array}$ & $\begin{array}{c}\text { Aula } 2 . \\
\text { Caracterização }\end{array}$ & $\begin{array}{c}\text { Aula 3. Experimen- } \\
\text { tos de adsorção }\end{array}$ \\
\hline Grupo 1 & $\begin{array}{l}\mathrm{NaOH} 10 \mathrm{~mol} \\
\mathrm{~L}^{-1} / 10 \mathrm{~min}\end{array}$ & \multirow{6}{*}{$\begin{array}{l}\text { Pesagem, } \\
\text { titulação e } \\
\text { inicio dos } \\
\text { experimentos } \\
\text { de adsorção. }\end{array}$} & \multirow{6}{*}{$\begin{array}{l}\text { Análise das } \\
\text { soluções após os } \\
\text { experimentos de } \\
\text { adsorção. }\end{array}$} \\
\hline Grupo 2 & $\begin{array}{l}\mathrm{NaOH} 10 \mathrm{~mol} \\
\mathrm{~L}^{-1} / 30 \mathrm{~min}\end{array}$ & & \\
\hline Grupo 3 & $\begin{array}{l}\mathrm{NaOH} 10 \mathrm{~mol} \\
\mathrm{~L}^{-1} / 60 \mathrm{~min}\end{array}$ & & \\
\hline Grupo 4 & $\begin{array}{l}\mathrm{HNO}_{3} 10 \mathrm{~mol} \\
\mathrm{~L}^{-1} / 10 \mathrm{~min}\end{array}$ & & \\
\hline Grupo 5 & $\begin{array}{l}\mathrm{HNO}_{3} 10 \mathrm{~mol} \\
\mathrm{~L}^{-1} / 30 \mathrm{~min}\end{array}$ & & \\
\hline Grupo 6 & $\begin{array}{c}\mathrm{HNO}_{3} 10 \mathrm{~mol} \\
\mathrm{~L}^{-1} / 60 \mathrm{~min}\end{array}$ & & \\
\hline
\end{tabular}

Neste conjunto de experimentos o professor pode discutir vários aspectos, i.e. o efeito do catalisador, tempo de hidrólise, determinação dos sítios ácidos e propriedades de adsorção. Se o professor desejar abordar um tópico mais específico os experimentos devem ser cuidadosamente preparados considerando: (i) tempo, (ii) números de estudantes/grupo, (iii) número de aulas e (iv) equipamentos disponíveis.

\section{Preparação do PET}

O PET incolor (por exemplo, $2 \mathrm{~g}$, de garrafas de refrigerante) deve ser cortado em pedaços quadrados de 5 x $5 \mathrm{~mm}$ lavados com água e secados. O PET também deverá ser cortado em dimensões de 20, 10 e $2 \mathrm{~mm}$, para o estudo da área superficial exposta. Para o refluxo, poderá ser utilizado $1 \mathrm{~g}$ of PET com $5 \mathrm{~mL}$ de solução aquosa de ácido ou base $\left(\mathrm{HNO}_{3}\right.$ ou $\left.\mathrm{NaOH}\right)$ em diferentes concentrações (por exemplo, 1,5 e $\left.10 \mathrm{~mol} \mathrm{~L}^{-1}\right)$. Soluções alcalinas altamente concentradas devem ser mantidas em frascos tampados para evitar reação com $\mathrm{CO}_{2}$ do ar formando bicarbonato.

\section{A reação de hidrólise}

Neste trabalho, as reações de hidrólise serão feitas sob refluxo. O refluxo garante a temperatura da reação constante. Os estudantes podem trabalhar com temperaturas baixas, porém: (i) temperaturas baixas são mais difíceis de se manterem constantes, e (ii) em temperaturas menores que $60^{\circ} \mathrm{C}$ a reação é muito lenta e nenhuma diferença significativa é observada no PET.

O refluxo pode ser feito em balão de fundo redondo de $20-50 \mathrm{~mL}$ conectados a um condensador. Alternativamente, podem ser utilizados tubos de ensaio longos $(15 \mathrm{~cm})$, mas atenção para manter a mistura reacional sob refluxo sem perder muito vapor. Para o refluxo podem ser utilizados um banho de óleo (300 mL) com silicone, glicerol ou mesmo óleo vegetal (por exemplo, óleo de soja), pré-aquecido a ca. 125 ${ }^{\circ} \mathrm{C}$. Após estabilização da temperatura o balão é imerso no banho de óleo e após 2 min do inicio do refluxo é monitorado o tempo de reação (por exemplo, 5, 10, 15, 30, 45 e $60 \mathrm{~min}$ ). Conferir se os pedaços de PET estão imersos na solução. A temperatura e o tempo de reação são muito importantes para a reprodutibilidade dos resultados.

\section{Purificação do PET após a hidrólise}

A purificação do PET após a hidrólise é uma etapa muito importante, uma vez que todos os resultados discutidos neste trabalho dependem da pureza do PET parcialmente hidrolisado. A Figura abaixo mostra esquematicamente as etapas de purificação realizadas após a hidrólise.

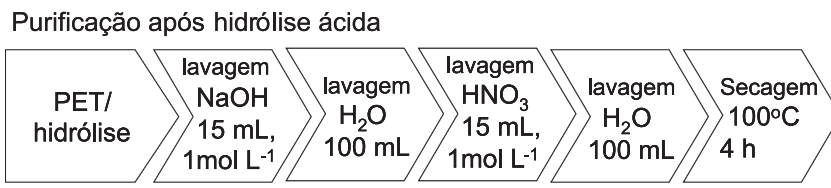

Purificação após hidrólise básica

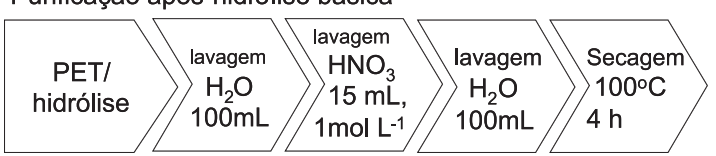

1- Após a hidrólise em meio ácido, uma solução de $\mathrm{NaOH}$ (15 $\mathrm{mL}, 1 \mathrm{~mol} \mathrm{~L}^{-1}$, com agitação por $5 \mathrm{~min}$ ) deve ser usada para solubilizar o ácido tereftálico sólido e removê-lo da superfície do PET.

2- Em seguida, o PET deve ser lavado com água destilada (30 mL, agitando por $5 \mathrm{~min}$ ) para remover o excesso de $\mathrm{NaOH}$. 
3- Lavar novamente com $\mathrm{HNO}_{3}\left(15 \mathrm{~mL}, 1 \mathrm{~mol} \mathrm{~L}{ }^{-1}\right.$, com agitação por $5 \mathrm{~min}$ ) para regenerar os grupos ácidos carboxílicos.

4- Posteriormente, o PET deve ser lavado novamente com água destilada ( 3 vezes com porções de $30 \mathrm{~mL}$ por 5 min cada) para retirar o excesso de $\mathrm{HNO}_{3}$. Nesta etapa, é importante verificar se o $\mathrm{pH}$ da água de lavagem está neutro para garantir que todo o excesso de ácido foi retirado.

5- Secar em forno a $100{ }^{\circ} \mathrm{C}$ por $4 \mathrm{~h}$. O PET deverá estar bem seco, uma vez que os resultados serão discutidos baseando-se em sua massa.

O mesmo procedimento é usado após a hidrólise alcalina, com exceção da primeira lavagem com $\mathrm{NaOH}$, que não é necessária.

\section{Determinação dos sítios ácidos por titulação}

Para determinação dos sítios ácidos, ${ }^{11} 30 \mathrm{mg}$ do PET parcialmente hidrolisado é misturado com 2,00 mL of $\mathrm{NaOH}\left(0,0500 \mathrm{~mol} \mathrm{~L}^{-1}\right)$ em um tubo de ensaio e agitado por $30 \mathrm{~min}$ (Equação 2S). Em seguida, 25,00 mL de água destilada é adicionada, e agitado por mais $3 \mathrm{~min}$. Coletar uma alíquota de 10,00 mL e titular com uma solução de biftalato de potássio 0,00150 mol L-1 usando fenolftaleína como indicador (Equação 3S). A partir da titulação é possível calcular o número de grupos ácidos presentes na superfície do PET como mmol de $\mathrm{H}^{+}(\mathrm{ou}-\mathrm{COOH})$ por $\mathrm{g}_{\mathrm{PET}}$.

$$
\begin{aligned}
& -\mathrm{COOH}_{\text {sup. }}+\mathrm{NaOH} \rightarrow-\mathrm{COO}^{-} \mathrm{Na}^{+}+\mathrm{NaOH}_{\text {exc }} \\
& \mathrm{NaOH}_{\text {exc }}+\mathrm{H}^{+} \mathrm{K}^{+}(\text {bift })^{2-} \rightarrow \mathrm{Na}^{+} \mathrm{K}^{+}(\text {bift })^{2-}
\end{aligned}
$$

\section{Experimentos de adsorção}

\section{Adsorção do corante azul de metileno}

O corante azul de metileno possui estrutura cationnica e pode ser usado como molécula modelo para os experimentos de adsorção:<smiles>CN(C)c1ccc2nc3ccc(=[W])cc-3sc2c1</smiles>

Os experimentos de adsorção ${ }^{11}$ foram feitos com soluções aquosas de azul de metileno em diferentes concentrações 5, 10, 25, 50, 100, 200 e $400 \mathrm{mg} \mathrm{L}^{-1} \mathrm{com} \mathrm{pH}$ natural de $6,3 \pm 0,3$. As isotermas de adsorção foram obtidas através do contato de $30 \mathrm{mg}$ de PET parcialmente hidrolisado com $20 \mathrm{~mL}$ de solução em um frasco fechado (para evitar a evaporação) por $12 \mathrm{~h}$ (tempo que garante que a adsorção entrou em equilíbrio). No entanto, experimentos realizados em nosso laboratório mostraram que mais de $90 \%$ do equilíbrio foi alcançado nas primeiras duas horas. Portanto, este experimento pode ser feito em um tempo curto, tendo em mente que um pequeno erro é introduzido.

Após a adsorção, a quantidade de azul de metileno adsorvida foi monitorada por medidas espectrofotométricas em $\lambda_{\text {max }} 627 \mathrm{~nm}$. Os estudantes devem obter uma curva de calibração com as soluções preparadas para os experimentos de adsorção.

Os experimentos de adsorção de $\mathrm{Cd}^{2+}$ (usando $\mathrm{CdCl}_{2}$ ) foram feitos exatamente da mesma maneira, porém com o pH da solução ajustado para 5,5 usando soluções de $\mathrm{HCl}$ ou $\mathrm{NaOH}$. $\mathrm{O} \mathrm{Cd}^{2+}$ adsorvido foi monitorado por absorção atômica. As isotermas de adsorção foram obtidas através do gráfico de concentração do adsorbato (corante ou $\mathrm{Cd}^{2+}$ ) após a adsorção (chamada de "concentração de equilíbrio") versus a capacidade de adsorção $\left(\mathrm{q}=\mathrm{m}_{\text {adsorbato }}\right.$ por $\left.\mathrm{g}_{\mathrm{PET}}\right)$.

\section{Cuidados especiais}

Cuidado com soluções básicas ou ácidas concentradas - óculos de segurança e avental de laboratório devem ser usados o tempo inteiro.
Cuidado especial com soluções concentradas de $\mathrm{HNO}_{3}$ pois liberam vapores ácidos altamente tóxicos e irritantes, suspeitos de provocarem câncer. Cloreto de cádmio também é altamente tóxico, suspeito de provocar câncer. O corante azul de metileno não apresenta qualquer efeito tóxico, porém o contato com a pele deve ser evitado.

\section{SUPORTE PARA DISCUSSÃO DOS RESULTADOS}

Diferenças entre hidrólise ácida e básica: alguns detalhes do experimento para serem considerados pelos estudantes

As reações em presença de catalisadores ácidos ou básicos têm diferenças importantes. O ácido tereftálico (AT), produto da hidrólise, é um ácido relativamente fraco, de baixa solubilidade em água (19 mg $\mathrm{L}^{-1}$ a $25^{\circ} \mathrm{C}$ ). Entretanto, para a hidrólise em meio ácido o AT formado será insolúvel e parte dele precipitará na superfície do PET como mostrado na Figura 3. Por outro lado, na hidrólise em meio básico o AT é solubilizado na forma de tereftalato $\mathrm{TA}^{2-}{ }_{\mathrm{aq}}$ (Figura 4).

$$
\begin{aligned}
& \mathrm{HOOCC}_{6} \mathrm{H}_{4} \mathrm{COOH}(\mathrm{s})+2 \mathrm{NaOH}(\mathrm{aq}) \rightarrow \mathrm{OOCC}_{6} \mathrm{H}_{4} \mathrm{COO}^{-}(\mathrm{aq})+ \\
& 2 \mathrm{Na}^{+}(\mathrm{aq})
\end{aligned}
$$

O etilenoglicol (EG) formado será solúvel em água em ambos os processos, catalisado por ácido ou base (Figura 3S).

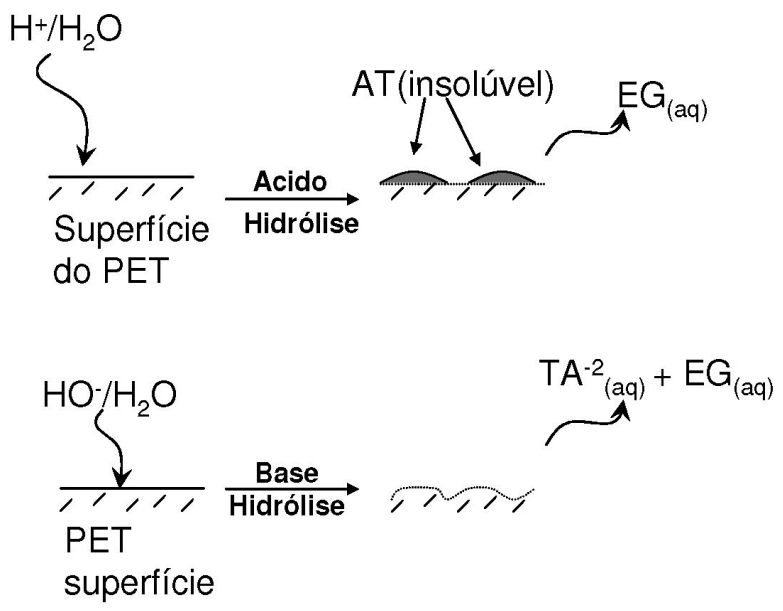

Figura 3S. Formação de ácido tereftálico (AT), insolúvel, na superfície do PET após hidrólise ácida e tereftalato $\left(T A^{-2}{ }_{a q}\right)$, solúvel, após hidrólise em meio básico

\section{RESULTADOS E DISCUSSÃO}

\section{Efeito da natureza e concentração do catalisador}

$\mathrm{O}$ artigo mostra somente resultados para o $\mathrm{NaOH}$. Resultados para o $\mathrm{KOH}$ foram também obtidos e estão apresentados abaixo (Figura 4S).

O rendimento da hidrólise foi calculado baseado no consumo do PET na reação de acordo com a Equação 5S:

Rendimento $(\%)=100 *\left(\mathrm{~m}_{\mathrm{i}}-\mathrm{m}_{\mathrm{f}}\right) / \mathrm{m}_{\mathrm{i}}(5 \mathrm{~S})$

onde: $m_{i}=$ massa do PET antes da reação e $m_{\mathrm{f}}=$ massa do PET após a reação.

Podem ser observados resultados semelhantes para $\mathrm{NaOH}$ e $\mathrm{KOH}$. Para concentração até $5 \mathrm{~mol} \mathrm{~L}^{-1} \mathrm{o}$ rendimento da hidrólise foi de ca. $10 \%$ após 120 min. Por outro lado, para concentrações de base de $10 \mathrm{~mol} \mathrm{~L}^{-1}$ mais de $90 \%$ do PET foi hidrolisado após 120 min, sob as condições de reação. É interessante observar o compor- 

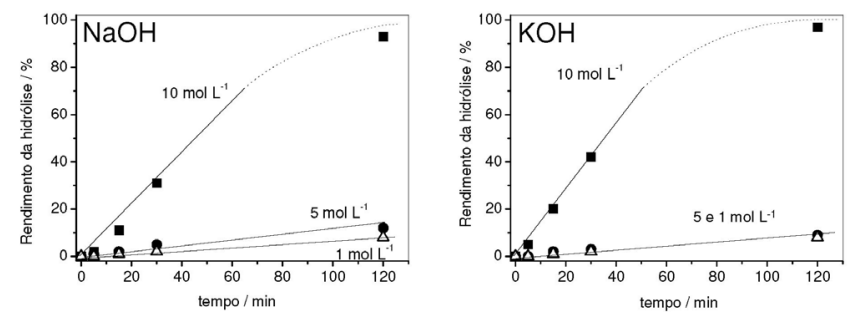

Figura 4S. Hidrólise do PET em presença de $\mathrm{NaOH}$ e $\mathrm{KOH}$ em diferentes concentrações (refluxo a $120^{\circ} \mathrm{C}, 1 \mathrm{~g}$ PET em $5 \mathrm{~mL}$ de solução)

tamento linear do gráfico de hidrólise, sugerindo uma dependência de pseudo-ordem zero.

Uma expressão de velocidade simples pode ser escrita como:

$\mathrm{V}_{\text {hidrólise }}=\mathrm{k}_{\text {hidrólise }}\left[\mathrm{H}_{2} \mathrm{O}\right]^{0}[\mathrm{PET}]^{0}$

A expressão considera que (i) a concentração de $\mathrm{H}_{2} \mathrm{O}$ é muito alta e não muda significativamente durante a reação, (ii) embora o PET seja consumido durante a hidrólise, a superfície do PET disponível para a reação não muda significativamente e (iii) a concentração de HO não varia consideravelmente durante a reação, mesmo considerando um consumo pela formação do ácido tereftálico, o qual reagiria com menos de $10 \%$ do $\mathrm{NaOH}$ presente na reação $\left(10 \mathrm{~mol} \mathrm{~L}^{-1}\right)$ se o PET fosse completamente convertido a AT. Para a reação com $10 \mathrm{~mol}$ $\mathrm{L}^{-1}$ após 60 min é observada uma perda da linearidade relacionada com o consumo de mais de $80 \%$ do PET presente na reação.

A Figura 5S mostra os resultados para hidrólise feita com $\mathrm{HNO}_{3}$ em diferentes concentrações.

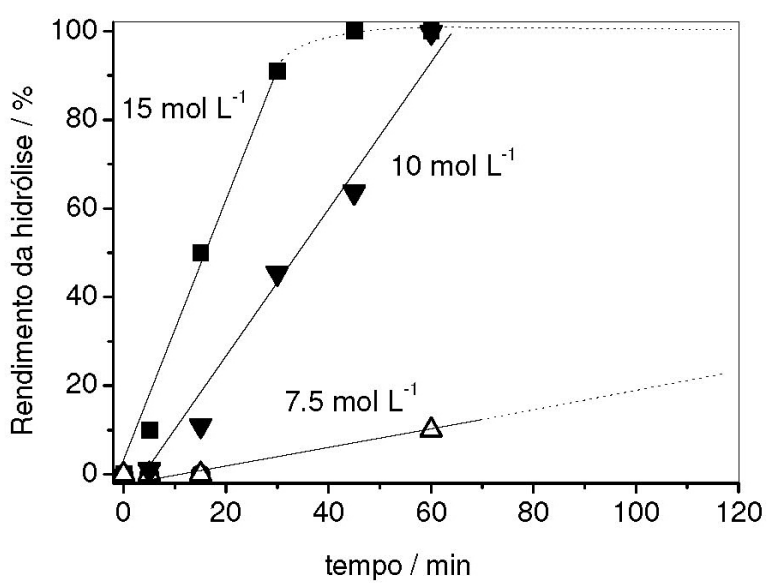

Figura 5S. Hidrólise do PET na presença de $\mathrm{HNO}_{3}$ em diferentes concentrações $\left(120^{\circ} \mathrm{C}, 1 \mathrm{~g}\right.$ PET em $5 \mathrm{~mL}$ de solução)

Observa-se que as reações na presença de $\mathrm{HNO}_{3}$ também mostram um comportamento linear, sugerindo uma cinética de pseudo-ordem zero.

As constantes de velocidade para as reações em presença dos diferentes catalisadores, i.e. $\mathrm{NaOH}, \mathrm{KOH}$ e $\mathrm{HNO}_{3}$, podem ser calculadas através da inclinação da reta e estão mostradas na Figura 6S. Como as reações foram feitas com $1 \mathrm{~g}$ de PET, as constantes de velocidade podem ser calculadas simplesmente por $\mathrm{K}_{\text {hidrólise }}=($ inclinação x $1 \mathrm{~g}$ )/100.

A Figura $6 \mathrm{~S}$ sugere que velocidades de reação apreciáveis foram obtidas apenas com concentrações de catalisador maiores que $7 \mathrm{~mol}$ $\mathrm{L}^{-1}$. Ainda, pode ser notado que a concentração de catalisador de 10 mol L-1 mostra constante de velocidade levemente maior para $\mathrm{HNO}_{3}$, seguido do $\mathrm{KOH}$ e $\mathrm{NaOH}$.

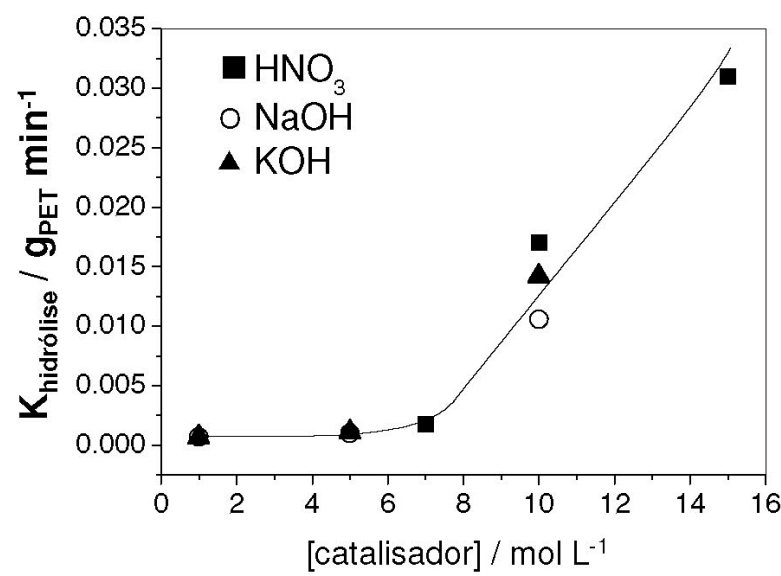

Figura 6S. Constantes de velocidade para as reações feitas na presença de $\mathrm{NaOH}, \mathrm{KOH}$ e $\mathrm{HNO}_{3}$

\section{O efeito da área exposta do PET na velocidade de hidrólise}

O efeito da área superficial exposta do polímero pode ser investigado usando pedaços de PET com diferentes tamanhos. A Tabela $2 \mathrm{~S}$ mostra a área superficial exposta estimada para PET cortados em diferentes dimensões (l).

Pode ser observado que o rendimento da hidrólise não muda significativamente quando os quadrados de PET são cortados com 5,10 e $20 \mathrm{~mm}$. Por outro lado, para pedaços com $2 \mathrm{~mm}$, onde a área exposta de PET aumenta 43\%, é observado um significante aumento no $\mathrm{k}_{\text {hidrólise }}$

É interessante observar que um aumento de $43 \%$ na área superficial para os pedaços com $2 \mathrm{~mm}$ aumenta a constante de hidrólise em apenas $13 \%$. Embora as razões para esta não linearidade ainda não estejam claras, pode ser considerado que quando os pedaços são muito menores e a área superficial é significativamente maior outros parâmetros controlam a velocidade da reação, tais como a difusão da água, catalisador ou produtos durante a reação.

\section{Recuperação de ácido tereftálico após a hidrólise}

Nesta parte do trabalho uma discussão dos aspectos técnicos e econômicos da hidrólise para produzir ácido tereftálico (AT) e etilenoglicol (EG) para a reciclagem do PET pode ser estimulante para os alunos. Por exemplo, tópicos tais como:

- a separação e purificação do AT e EG do meio reacional para hidrólise ácida e básica (por exemplo, separação do AT e EG do catalisador e água, cristalização do AT e destilação no EG);

- os usos industriais do AT e EG (por exemplo, o uso do AT e EG para produzir PET, a importância da pureza do AT e EG obtidos, e outros usos do EG na indústria química);

- a reciclagem dos ácidos e bases usados como catalisador.

Como uma atividade adicional no laboratório, os estudantes podem trabalhar com a recuperação do AT após a hidrólise ácida através de simples filtração ou centrifugação. O pó cristalino branco pode ser lavado com uma solução ácida (por exemplo, $\mathrm{HNO}_{3} 1 \mathrm{~mol}$ $\mathrm{L}^{-1}$ ) para evitar a perda através da solubilização.

Ainda, a purificação por recristalização pode ser feita através da solubilização do AT com água quente e resfriando a temperatura ambiente. O AT obtido pode ser seco a $100^{\circ} \mathrm{C}$ por $4 \mathrm{~h}$ e a pureza calculada pela titulação com $\mathrm{NaOH}$. Não é possível verificar a pureza do AT através da temperatura de fusão, devido ao alto ponto de fusão $\left(425^{\circ} \mathrm{C}\right)$.

Para a hidrólise básica, o AT é solubilizado durante a reação. Para recuperar o AT após a reação é necessária a acidificação do meio reacional. 
Tabela 2S. PET cortados em quadrados em diferentes dimensões (1), área relativa exposta e constantes de velocidade de hidrólise ( $k$ )

\begin{tabular}{lcc}
\hline 1 & Área relativa exposta & Constante de hidrólise \\
\hline$/ \mathrm{mm}$ & $\mathrm{a}$ & $/ \mathrm{g}_{\mathrm{PET}} \mathrm{min}^{-1}$ \\
20 & 0.0170 \\
10 & 0.0170 \\
5 & 105 & 0.0175 \\
2 & 114 & 0.0192 \\
\hline
\end{tabular}

a- a área exposta foi calculada através da equação $A=2 \cdot 1^{2}+(4 \cdot 1 . x)$. A área exposta relativa foi obtida considerando $1=20 \mathrm{~mm}$ como referencia $100 \%$ com $\mathrm{x}=0.5 \mathrm{~mm}$.

\section{Caracterização do PET hidrolisado parcialmente}

Os estudantes podem recuperar o PET após a hidrólise e trabalhar na sua caracterização visual, flexibilidade e determinação dos sítios ácidos superficiais por titulação. Pode ser utilizado o PET hidrolisado com $\mathrm{HNO}_{3}$ ou $\mathrm{NaOH}$ a $10 \mathrm{~mol} \mathrm{~L}^{-1}$, onde aproximadamente $40 \%$ do PET original foi hidrolisado. Como discutido na parte experimental, para esta parte do trabalho é muito importante a purificação do PET hidrolisado com $\mathrm{HNO}_{3}$ através da extensiva lavagem com solução de $\mathrm{NaOH} 0,1 \mathrm{~mol} \mathrm{~L}^{-1}$ para remover o AT da superfície do PET.

Uma inspeção visual mostra diferenças importantes entre as hidrólises ácida e básica. O PET parcialmente hidrolisado com base como catalisador não mostra diferenças significativas do PET original, apresentando boa flexibilidade e transparência. Por outro lado, após a hidrólise ácida o material obtido é completamente diferente, ou seja, o material apresenta-se como um sólido branco e opaco, frágil e quebradiço. Na Figura $7 \mathrm{~S}$ são mostradas microscopias eletrônicas de varredura, dando aos estudantes uma idéia melhor do PET parcialmente hidrolisado em presença de catalisadores ácidos e básicos.

\section{Superfície}

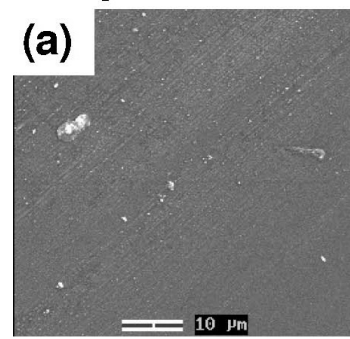

(b)
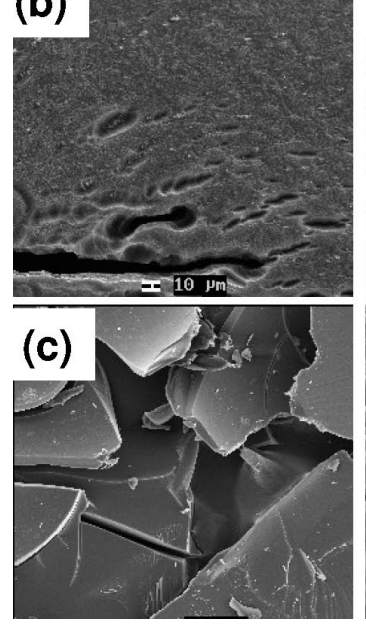

Figura 7S. MEV do: (a) PET original, (b) PET após a hidrólise com $\mathrm{NaOH}$ e (c) PET após hidrólise com $\mathrm{HNO}_{3}$ (catalisador $10 \mathrm{~mol} \mathrm{~L}^{-1}, 120^{\circ} \mathrm{C}, 30 \mathrm{~min}$ )
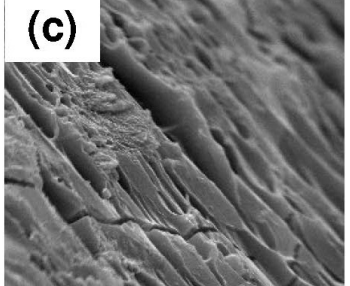

Pode ser observado que o PET original (de garrafas de refrigerante) mostra uma superfície lisa e regular. Após a hidrólise com $\mathrm{NaOH}$, a superfície ainda se apresenta lisa, porém com várias cavidades e fissuras. Por outro lado, a microscopia revela claramente que após a hidrólise com $\mathrm{HNO}_{3}$ o material se torna quebradiço, com grande quantidade de rachaduras e defeitos. Estes defeitos contêm cadeias poliméricas com terminações $-\mathrm{COOH}$ e $-\mathrm{CH}_{2} \mathrm{CH}_{2} \mathrm{OH}$ (Figura 8S). Por outro lado, a hidrólise alcalina acontece de maneira regular, produzindo principalmente ácido tereftálico e etilenoglicol. É conhecido da literatura que a hidrólise alcalina ataca preferencialmente regiões amorfas, levando a um PET mais cristalino. Como resultado dessa hidrólise regular uma superfície lisa é produzida com baixa concentração de defeitos. Estes resultados explicam a baixa concentração de sítios ácidos produzidos por hidrólise básica em comparação com a grande quantidade de sítios ácidos produzidos pela hidrólise com $\mathrm{HNO}_{3}$.

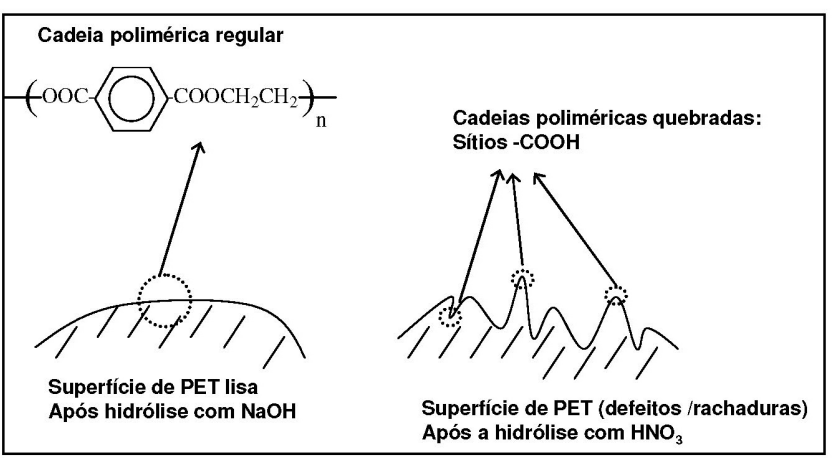

Figura 8S. Representação esquemática dos defeitos e rachaduras produzidos no PET após a hidrólise ácida

\section{Determinação dos sítios ácidos}

A hidrólise parcial de cadeias de poliéster deve produzir grupos ácidos carboxílicos e $(-\mathrm{COOH})$ e álcool $(-\mathrm{OH})$ ligados às cadeias poliméricas na superfície do PET (Figura 9S)

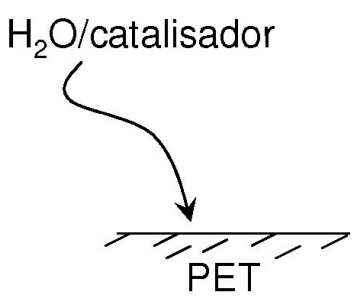

\section{Sítio ácido}

Figura 9S. Representação esquemática da formação de grupos ácidos carboxílicos na superfície do PET parcialmente hidrolisado 
O número de grupos ácido carboxílicos na superfície do PET hidrolisado pode ser determinado por simples titulação com NaOH. ${ }^{11-16}$

Atenção Antes da titulação, o PET hidrolisado deve ser cuidadosamente limpo como descrito na parte experimental. O PET hidrolisado com ácido deve ser extensivamente lavado com $\mathrm{NaOH}$ para remover todo o AT depositado em sua superfície. Após a lavagem com $\mathrm{NaOH}$ o ácido carboxílico da superfície deve ser neutralizado.

$-\mathrm{COOH}_{\text {sup }}+\mathrm{NaOH}_{\text {aq }} \rightarrow-\mathrm{COO}_{\text {sup }}^{-} \mathrm{Na}_{\text {aq }}^{+}$

Entretanto, após a lavagem com $\mathrm{NaOH}$ o PET hidrolisado deve ser lavado com solução de $\mathrm{HNO}_{3}$ para regenerar todos os sítios ácidos. (Equação 8S) e o excesso de $\mathrm{HNO}_{3}$ removido lavando com água:

$-\mathrm{COO}_{\text {sup }}^{-} \mathrm{Na}_{\text {aq }}^{+}+\mathrm{HNO}_{3 \mathrm{aq}} \rightarrow-\mathrm{COOH}_{\text {sup }}$

As titulações foram feitas adicionando $\mathrm{NaOH}$ em excesso que foi contra-titulado com $\mathrm{HCl}$. A concentração de sítios ácidos superficiais para o PET hidrolisado com $\mathrm{HNO}_{3}$ e $\mathrm{NaOH}$ para diferentes tempos de reação é mostrada na Figura 10S.

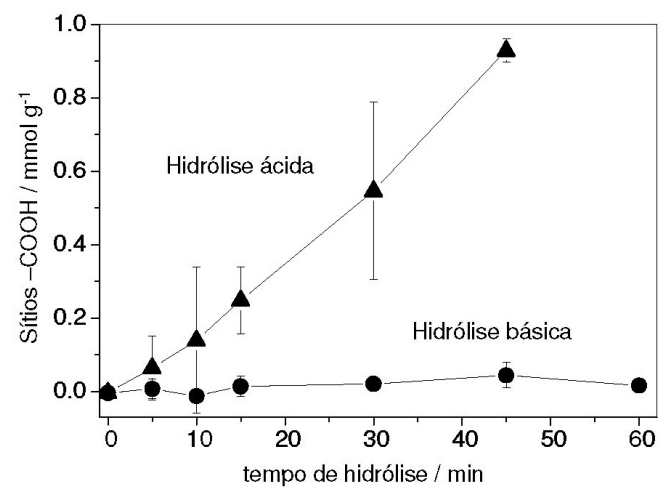

Figura 10S. Sítios ácidos carboxílicos para PET hidrolisado com $\mathrm{HNO}_{3}$ e $\mathrm{NaOH}\left(120^{\circ} \mathrm{C}\right.$, catalisador $\left.10 \mathrm{~mol} \mathrm{~L}^{-1}\right)$

\section{Determinação dos sítios ácidos por TG}

Se os estudantes tiverem acesso a um aparelho de termogravimetria, a concentração de sítios ácidos pode ser determinada. A análise termogravimétrica nos mostra o perfil da perda de massa do material quando submetido a um aquecimento controlado de temperatura. O polietileno tereftalato é um polímero estável termicamente até aproximadamente $400{ }^{\circ} \mathrm{C}$, portanto, a curva TG do polímero puro não apresenta perda de massa significativa até esta temperatura. No entanto, após a hidrólise parcial da superfície do PET são criados sítios ácidos - $\mathrm{COOH}$ na sua superfície. Os sítios - $\mathrm{COOH}$ formados se decompõem a temperaturas próximas a $200{ }^{\circ} \mathrm{C}$, formando $\mathrm{CO}_{2}$, o que provoca uma diminuição da massa do material. A através da perda de massa nesta região pode ser calculado o número de sítios ácidos. ${ }^{17}$

Tabela 3S. Comparação do número de sítios ácidos determinados por titulação e por TG (refluxo, $30 \mathrm{~min}$, catalisador $10 \mathrm{~mol} \mathrm{~L}^{-1}$ )

\begin{tabular}{lccc}
\hline Amostra & $\begin{array}{c}\text { Perda de massa Sítios ácidos por } \\
\text { TG } / \mathrm{mmol} \mathrm{g}^{-1}\end{array}$ & $\begin{array}{c}\text { Sítios ácidos } \\
\text { por titulação / } \\
\text { mmol g-1 }^{-1}\end{array}$ \\
\hline PET original & 0,60 & 0,00 & 0,003 \\
Hidrólise neutra & 0,65 & 0,01 & 0,016 \\
Hidrólise básica & 0,71 & 0,02 & 0,021 \\
Hidrólise ácida & 2,70 & 0,47 & 0,547 \\
\hline
\end{tabular}

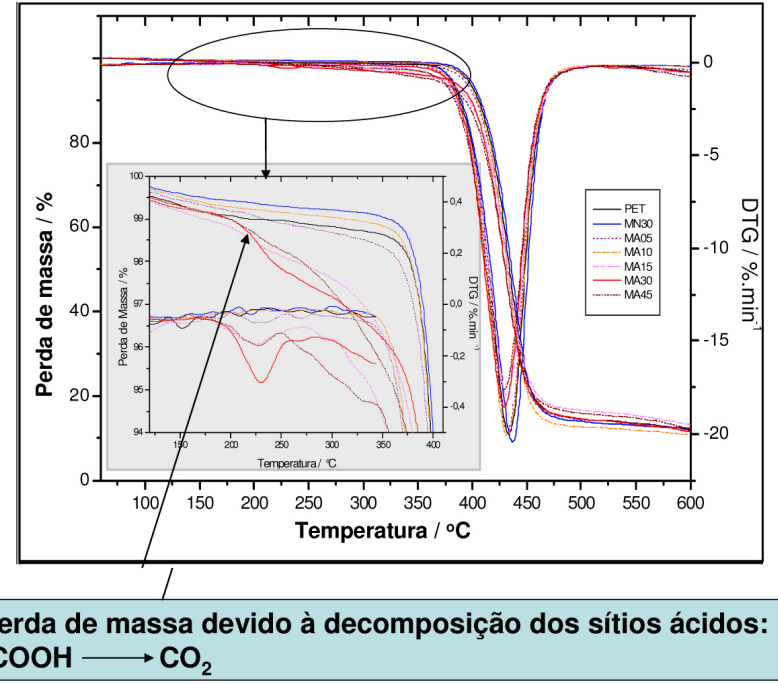

Figura 11S. Curva TG para o PET hidrolisado com $\mathrm{HNO}_{3}$ e $\mathrm{NaOH}(10 \mathrm{~mol}$ $\left.L^{-1}\right)$ sob refluxo por diferentes tempos

\section{REFERÊNCIAS}

1. Kaufman, D.; Wright, G.; Kroemer, R.; Engel, J.; J. Chem. Educ. 1999, 76,1525 .

2. Nikles D. E.; Farahat, M.S.; Macromol. Mat. Eng. 2005, 290, 13.

3. Soderberg, D. J.; Lenton, R. A.; Boylett, A. R.; Hicks, D. A.; Cell. Polym. 1993, 12, 421.

4. Kumar, S.; Guria, C.; J. Macromol. Sci. Pure Appl. Chem. 2005, 42, 237.

5. Goje, A. S.; Thakur, S. A.; Diware, V. R.; Chauhan, Y. P.; Mishra, S.; Polym. Plast. Technol. Eng. 2004, 43, 407.

6. Dannoux, M.; Cassagnau, P.; Michel, A.; Can. J. Chem. Eng. 2002, 80, 1075.

7. Colomines, G.; Rivas, F.; Lacoste, M. L.; Robin, J. J.; Macromol. Mat. Eng. 2005, 290, 710.

8. Baldissera, A. E.; Valerio, C. E. S.; Basso, N. R. D.; Guaragna, F.; Einloft, S.; Tessier, M.; Fradet, A.; Quim. Nova 2005, 28, 188.

9. Yoshioka, T.; Okayama, N.; Okuwaki, A.; Ind.Eng.Chem. Res. 1998, 37, 336.

10. Yoshioka, T.; Motoki, T.; Okuwaki, A.; Ind.Eng.Chem.Res. 2001, 40, 75.

11. Costa, L. C. M.; Araujo, M. H.; Sapag, K.; Sardella, M. F.; Silva, H.; Deiana, A. C.; Lago, R. M.; J. Braz. Chem. Soc. 2005, 16, 899.

12. Busch, O. M.; Brijoux, W.; Thomson, S.; Schüth, F.; J. Catal. 2004, 222, 174.

13. Marques, J. P.; Gener, I.; Ayrault, P.; Bordado, J. C.; Lopes, J. M.; Ribeiro, F. R.; Guisnet, M.; Microp. Mesop. Mat. 2003, 60, 251

14. Palomino, G. T.; Pascual, J. J. C.; Delgado, M. R.; Parra, J. B.; Areán, C. O.; Mat. Chem. Phys. 2004, 85, 145.

15. Stevens, Jr, R. W.; Chuang, S. S. C.; Davis, B. H.; Appl. Catal. A 2003 , 252, 57 .

16. Yuan, P.; Wu, D. Q.; He, H. P.; Lin, Z. Y.; Appl. Surf. Sci. 2004, 227, 30.

17. Rios, R. R. V. A.; Gontijo, M.; Ferraz, V. P.; Lago, R. M; Araújo, M. H.; J. Braz. Chem. Soc. 2006, 17, 603. 